\section{The American Association for Thoracic Surgery}

\section{AATS Week 2014}

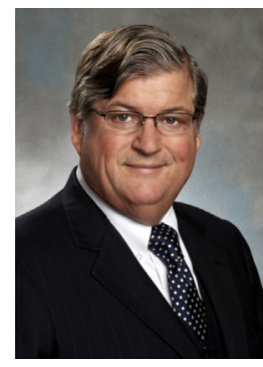

\section{Dear Colleagues,}

I would like to personally invite you to experience AATS Week 2014. The week begins with intensive instruction at the 2-day Aortic Symposium in New York City (April 24-25, 2014) and then moves to Toronto (94th Annual Meeting, April 26-30) where you will see the best science in our specialty with a focus on accomplishing skills essential to becoming a master surgeon and educator. (Discount airfares are available from New York to Toronto listed on the AATS Web site.)

From its outset, the Annual Meeting will feature new sessions including the completely revamped Skills and Postgraduate courses. The full-day Saturday skills courses will be followed by hands-on learning sessions on Saturday evening available by separate ticket. On Sunday the PG courses will consist of new rapid-fire presentations from leaders in their respective fields and joint sessions between the congenital and adult courses in the afternoon. The PG courses feature a "Legends" luncheon that will have presentations by Drs Alain Carpentier, Aldo Castaneda, and F. Griffith Pearson, who will impart their perspectives on their careers as pioneers in cardiothoracic surgery.

A new single ticket format for the Saturday and Sunday courses will allow attendees to move freely between sessions to participate in various talks of interest.

The exhibit hall activities will emphasize outreach to young surgeons with "Top Gun" technical competitions as well as scientific poster sessions for national and international residents along with a new "Surgeon of the Future" program.

In addition to a first-rate scientific program developed from a record number of abstract submissions, the contributions of past AATS presidents will be highlighted through a series of biographies interspersed within the plenary sessions. During the simultaneous sessions new national guidelines in the fields of thoracic and cardiac surgery will also be presented.

Following on the theme of becoming a master surgeon and educator, we have invited two guest speakers to share their vision of leadership. Rick Pitino, the master coach of the 2013 national collegiate basketball champion Louisville Cardinals and New York Times bestseller, will talk about the principles of coaching that we can apply to educating our residents. Margaret "Coach Meg" Moore, a coach of coaches, will help us to understand the neuroscience of effective coaching and the way in which the brain adapts to master coaching for life-long improvement in judgment and technical skill.

These lectures complement the concepts of "Clarity of Purpose and Focused Attention, the Essence of Excellence" that I will introduce during the 94th Presidential Address.

The meeting concludes on Wednesday with a new must see, Masters of Cardiothoracic Surgery, "Live" video series, featuring procedures done and narrated by the leaders and luminaries of our specialty. This will be followed by the fiery debates and popular TCT program later in the day.

This is Toronto, an international city, where, coincidentally, I trained in thoracic surgery. The city has everything one could want in a meeting venue.

The leadership of the AATS looks forward to welcoming all of you to this innovative AATS Week 2014, which begins in New York with the Aortic Symposium and culminates in Toronto with the 94th Annual Meeting. The week will provide a truly international experience where your skills can be retooled and your outlook recharged for our specialty of cardiothoracic surgery. See you there!!

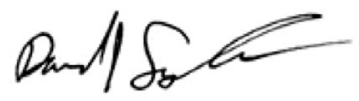

David J. Sugarbaker, MD

\section{AATS Aortic Symposium 2014}

April 24-25, 2014

New York Hilton Midtown

New York, New York

\section{Course Directors:}

Joseph S. Coselli

Houston, Texas

Steven L. Lansman

New York, New York

AATS AORTIC SYMPOSIUM 2014 is a two-day symposium focused on the pathophysiology, diagnosis, and treatment of aortic aneurysms and dissections. This conference is designed for cardiovascular and thoracic surgeons, residents, perfusionists, ICU and OR nurses, and those involved with the care of individuals with aortic disease. The Aortic Symposium primarily features invited faculty presentations of original work or "state-of-the-art reviews" where world 
leaders in this field share their experience regarding difficult problems in aortic disease. Manuscripts selected from submitted abstracts will comprise the balance of the program and be considered for publication in a supplement of the Journal of Thoracic and Cardiovascular Surgery.

\section{PROGRAM NOW ONLINE}

View the AATS AORTIC SYMPSOIUM 2014 program online at www.aats.org/aortic.

\section{*NEW THIS YEAR* \\ BREAKFAST SESSIONS \\ Friday, April 25, 2014}

\section{Controversies in Aortic Surgery}

6:00-7:00 AM

Focusing on 2 areas of controversy in aortic surgery:

- Dr Steven Lansman and Dr Roberto Di Bartolomeo, respectively, will discuss the pros and cons of extending the classical repair for type A dissection with a descending endograft.

- Dr D. Craig Miller and Dr Hans-Joachim Schäfers, respectively, will discuss re-implantation and remodeling for valve-sparing aortic root replacement.

An informal discussion session will follow each topic.

\section{Stump the Stars}

6:00-7:15 AM

Participants will be asked to submit diagnostically or technically challenging cases, summarized in 5 slides (eg, 2-4 work up/imaging and 1-2 OR findings/outcome). Selected submissions will be presented to faculty members and opened for discussion before the findings/outcomes are presented.

May attend one of the following:

- Stump the Stars: Endovascular Cases Moderators: Joseph E. Bavaria

Eric E. Roselli

- Stump the Stars: Open Surgery Cases Moderators: Nicholas T. Kouchoukos David Spielvogel

SEATING IS LIMITED for these two sessions and will be filled on a first come, first served basis. Instructions on how to submit cases will be forwarded in the near future.

The American Association for Thoracic Surgery is accredited by the Accreditation Council for Continuing Medical Education to provide continuing medical education for physicians.

This activity has been approved for 14.75 AMA PRA Category 1 Credits $^{\mathrm{TM}}$.

\section{AATS 94th Annual Meeting}

April 26-30, 2014

Metro Toronto Convention Centre

Toronto, Canada
Join us at the Metro Toronto Convention Centre in Toronto, Ontario, Canada, April 26-30, 2014, for the American Association for Thoracic Surgery's 94th Annual Meeting. This internationally recognized, highquality five-day program, co-chaired by AATS President David J. Sugarbaker, MD, and Raphael Bueno, MD, is designed with a primary focus on delivering cutting-edge education to improve cardiothoracic surgical practice. Gather with the world's foremost scientists and medical professionals in the specialty at this premier continuing medical education event.

Don't miss the Saturday and Sunday Symposia including: Saturday, April 26th

- Adult Cardiac Skills and Decision Making: Pearls and Pitfalls in Operative Technique Course Chair: Tomislav Mihaljevic

- Congenital Skills and Decision Making: Developing Technical Excellence Course Chair: J. William Gaynor

- General Thoracic Skills and Decision Making: Mastering Techniques and Decision Making Course Chair: Nasser K. Altorki

- Cardiothoracic Transplant and Mechanical Circulatory Support of Heart and Lung: Mastery of the Management of End-Stage Heart and Lung Failure

Course Chair: R. Duane Davis

- Allied Health Personnel Symposium: Advancing the Practice of Patient Care in Cardiothoracic Surgery Course Co-chairs: Stephen C. Yang and Katherine J. Hoercher

Sunday, April 27th

- AATS/STS Adult Cardiac Surgery Symposium: Becoming a Master Valve Surgeon Course Chair: David H. Adams

- AATS/STS Congenital Heart Disease Symposium: Issues Beyond the Textbook Course Chair: Ivan M. Rebeyka

- AATS/STS General Thoracic Surgery Symposium: Becoming a Master Thoracic Surgeon Course Chair: Scott J. Swanson

- AATS/STS Cardiothoracic Critical Care Symposium: Respiratory Failure Course Co-chairs: Michael S. Mulligan and Nevin M. Katz

\section{NEW FOR 2014!}

AATS Postgraduate Symposia Legends Lunch

Renowned cardiothoracic surgeons will share their experiences during the interactive Legends Lunch on Sunday 